\title{
Study of Wind Turbine Noise Propagation Characteristics Considering Geographical Features
}

\author{
Bong-Young Kim¹, Zhixing Tian² and Myung-Jin Bae ${ }^{3 *}$ \\ ${ }^{1}$ Soong-sil University, Department of Information and telecommunication Engineering, Seoul, 06978, Korea \\ Orcid Id : 0000-0002-3553-039X \\ ${ }^{2}$ Soong-sil University, Department of Information and telecommunication Engineering, Seoul, 06978, Korea \\ Orcid Id : 0000-0003-3882-2459 \\ ${ }^{3}$ Soong-sil University, Department of Information and telecommunication Engineering, Seoul, 06978, Korea \\ Orcid Id : 0000-0002-7585-0400
}

\begin{abstract}
:
Wind turbines generate low frequency noise from turbulence between the blades and the wind, causing physical and mental distress to nearby residents. In order to minimize noise damage from wind turbines, offshore wind turbines are installed, and 'Tamra Offshore Wind Power' on Jeju Island is an excellent example of minimizing noise damage. In this study, the propagation path of wind turbine noise was predicted while considering the geographical features as well as noise propagation characteristics of mountainous and coastal areas where wind turbines are installed. As a result of predicting the propagation path of wind turbine noise in mountainous and coastal areas, it was expected that the noise would spread far at night due to the winds in mountainous areas causing distress to residents. In coastal areas where the sea and land breeze constantly blow, it was expected that the noise of the wind turbines will be refracted upwards during both night and day, minimizing distress from noise for residents. It is hoped that this study will help select the location of wind turbines to minimize noise damage to residents.
\end{abstract}

Keyword: Wind Turbine, Noise, Propagation Path, Mountainous Area, Coastal Area

\section{INTRODUCTION}

Wind power is a renewable energy source with no carbon emission that produces energy without any additional raw materials. Wind turbine has attracted attention and was noted as a pollution free energy source as well as an economical energy source by converting the natural energy of wind power into electricity. However, the low frequency noise generated by the wind turbine blades and wind turbulence undermines its title of being eco-friendly and pollution free. Low frequency noise from wind turbines causes physical and mental distress, and the construction of wind power generators are often delayed for many years or are halted indefinitely due to residents being concerned about environmental damage [1-4].
Some scholars and environmentalists rationalize the negligent installation of wind turbines on the basis that damage from low frequency noise has not been proven. However, the logic that damage will not occur as it has not been verified is merely a selfish argument that ignores the lives of residents who will be directly affected by the actual environmental damage. Additionally, despite the lack of academic verification, there have been reports of physical and mental damage from low frequency noise generated from wind turbines, and the World Health Organization (WHO) also reported that low frequency noise poses major health problems. Therefore, it is important to select a location that minimizes noise damage from wind turbines and to draw the consent of residents rather than claiming that wind turbine noise is not a problem [3-5].

Among the wind turbine facilities in Korea, 'Tamra Offshore Wind Power' on Jeju Island is an incredibly successful power plant construction example. The offshore wind power generator is installed not only far from the residents, but also consists of geographical advantage of the sea which minimizes the damage of low frequency noise [5-7].

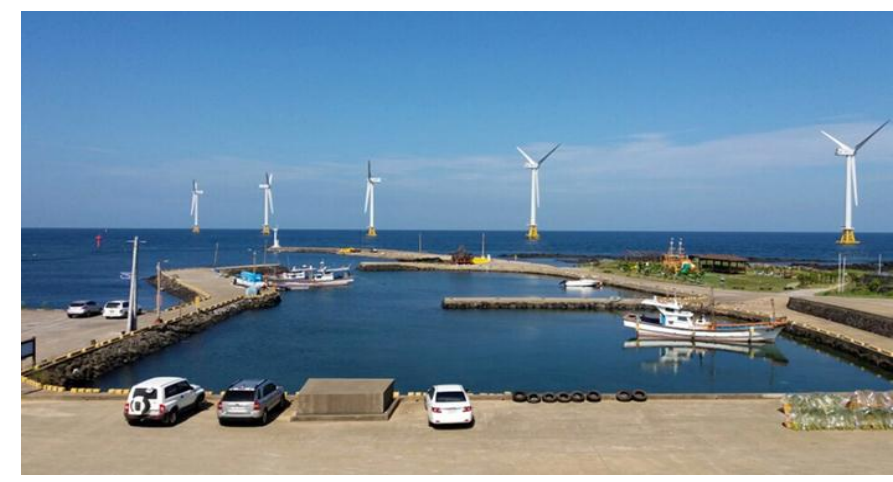

Fig 1. Tamra Offshore Wind Power 
In this study, the effects of temperature and geographical characteristics on the noise of offshore wind turbines were predicted. Thus, the purpose of this study was to examine the advantages of the offshore characteristics in the installation of wind turbines. Section 2 describes the propagation characteristics of sound from temperature differences and wind, and section 3 describes the geographical characteristics of land and sea affecting the propagation of noise. In section 4 , the propagation path of wind turbine noise on land and offshore, taking temperature and geographical characteristics into account, is estimated. Section 5 concludes the studyer generators are often delayed for many years or are halted indefinitely due to residents being concerned about environmental damage [1-4].

\section{PROPAGATION CHARACTERISTICS OF VARIOUS SOUNDS IN TEMPERATURE AND WIND}

\subsection{Propagation Speed of Sound}

The propagation speed of sound (c) can be expressed as the product of wavelength $(\lambda)$ and frequency ( $f$ ), and the relationship of sound pressure $(\mathrm{P})$ is expressed as shown in equation (1) [8].

$$
\begin{aligned}
& P=(\rho c) \vee[\mathrm{Pa}](1) \\
& \rho c: \text { Acoustic impedance (rayl) } \\
& \rho: \text { Density of medium }\left(\mathrm{Kg} / \mathrm{m}^{3}\right) \\
& v: \text { Particle velocity }(\mathrm{m} / \mathrm{s})
\end{aligned}
$$

Through such relationship, the sound velocity in air at temperature $(\theta)$ is expressed in equation 2 [8-9].

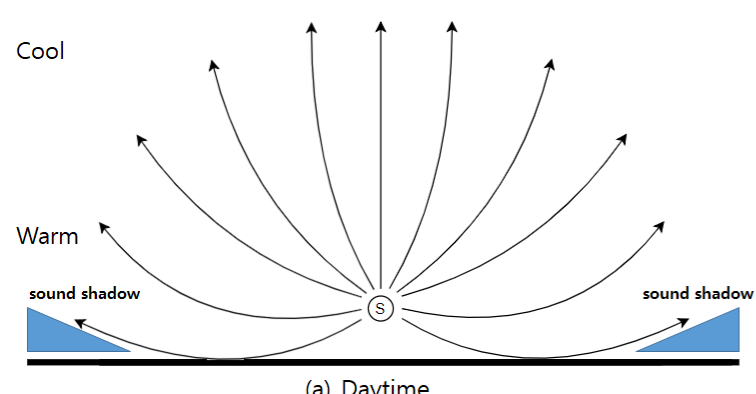

Fig 2. Refraction of sound waves according to air temperature distribution [8]

$$
\begin{aligned}
& c=c^{0}+0.61 \theta(2) \\
& c^{0}: 0^{\circ} \mathrm{C} \text { Sound velocity in air, } 331.5 \mathrm{~m} / \mathrm{s} \\
& \theta: \text { Temperature }\left[{ }^{\circ} \mathrm{C}\right]
\end{aligned}
$$

It can be seen from the relationship of equation (2) that the higher the temperature, the faster the propagation speed of sound.

\subsection{Refraction of Sound by Temperature}

As the Earth rotates, the amount of sunlight the surface of the Earth receives changes over time. During daytime, when the sun is high, the surface heats up quickly, whereas at night, the surface cools down quickly. This phenomenon causes the air in the lower level to warm up and air in the higher level to cool down during the day. Here, if the sound propagates, the difference in the propagation speed of sound is caused by the difference of temperature as shown in equation (2), and according to Snell's law as shown in equation (3), the propagation speed of sound is refracted to the lower level. Figure 2 shows sound being refracted and propagated by the temperature difference between the upper and lower level of the air. During daytime when sound is refracted upward and propagates, an inaudible sound shadow is generated as shown in Figure 2. On the other hand, at night when the temperature in the lower level is low, sound refracts to the ground and propagates farther [8-11]

$$
\frac{c_{1}}{c_{2}}=\frac{\operatorname{Sin} \theta_{1}}{\operatorname{Sin} \theta_{2}}
$$

\section{$c_{1}, c_{2}$ : Wave propagation speed of media 1 and $2[\mathrm{~m} / \mathrm{s}]$ \\ $\theta_{1}, \theta_{2}:$ Incidence and refraction angles of wavelengths in media 1 and 2}

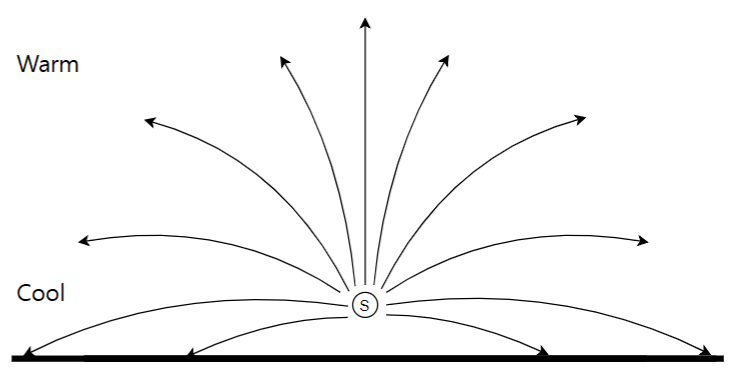

(b) Nighttime

\subsection{Wind Induced Sound Refraction}

Wind is formed by the pressure difference between two points. Such wind affects the speed of sound propagation by moving the media along the path of sound propagation. If a sound propagating at a speed of $340 \mathrm{~m} / \mathrm{s}$ is transmitted through a tailwind of $10 \mathrm{~m} / \mathrm{s}$, the propagation speed of the sound is 
$350 \mathrm{~m} / \mathrm{s}$, while a sound that is transmitted through a headwind of $10 \mathrm{~m} / \mathrm{s}$, the propagation speed of that sound will be $330 \mathrm{~m} / \mathrm{s}$. The movement of the medium by the wind causes a difference in the sound propagation speed of the upper and lower levels, thus sound is refracted and propagated. Wind blows at a higher rate in the upper levels, however, the wind speed decreases near the surface of the ground due to friction. Winds with reduced speed due to frictional forces near the ground are called surface winds and occur at a height below $1 \mathrm{~km}$ above the ground. Figure 3 shows the refraction and propagation of sound under headwind and tailwind along the sound propagation path. As shown in Figure 3, if a headwind blows on the sound propagation path, the sound rises upward generating a sound shadow, and if a tailwind blows on the sound propagation path, the sound falls downward and propagates farther [8-10][12].

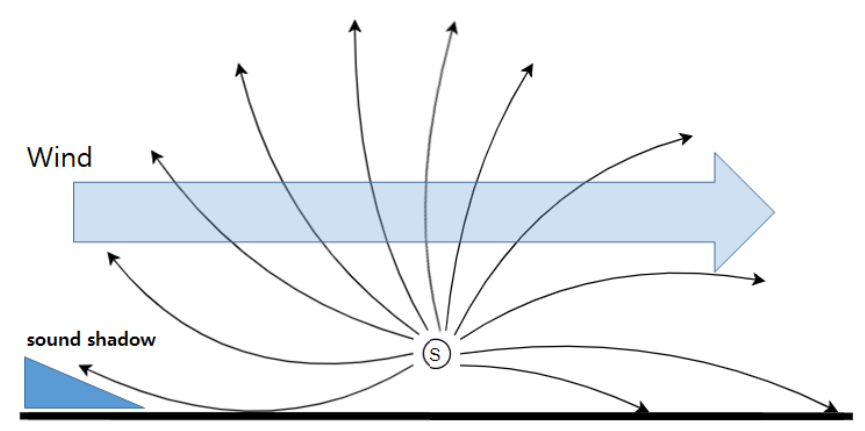

Fig 3. Sound refraction caused by wind [8]

\section{WIND FORMATION IN ACCORDANCE TO TOPOGRAPHIC CHARACTERISTICS}

\subsection{Mountain and Valley Breeze}

Mountain breeze and valley breeze are winds that blow due to the topographic features of mountainous regions. Mountain breeze and valley breeze refers to winds blowing from the mountaintops to the mountain valley at night, and winds blowing from the mountain valley to the mountaintop during the day, respectively. During daytime when the sun is high, the top of the mountain heats up faster than the valley region, and as the air rises, an air pressure difference occurs and wind from the valley blows. In addition, at night, the mountaintop cools relatively quickly, causing air to drift due to air pressure difference causing wind from the mountaintop to blow. Figure 4 shows mountain and valley winds caused by temperature differences in mountainous areas [13].

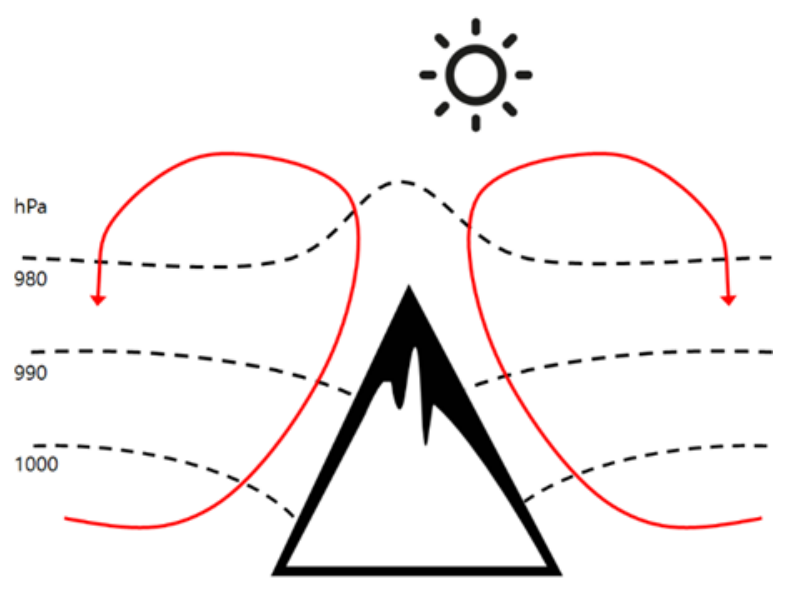

Fig 4. Mountain and valley winds in mountainous areas [13]

\subsection{Sea and Land Breeze}

Sea and land breeze blow from the coast or large adjacent lakes. These winds are caused by the rapid heating of the land during the day, due to the specific heat difference between the surface and the water, and by rapid cooling of the land at night. The surface of the earth heats up and cools down rapidly because its specific heat is about $1 / 3$ of that of the sea surface. This is why sea breeze occurs when the land gets hot during the day, and land breeze occurs when the land gets cold during the night. Due to the large temperature difference between the sea and land during the day, sea breezes generally blow harder than land breezes [14].

At about less than $1 \mathrm{~km}$ above ground, wind strength decreases toward the surface of the land due to the friction of the ground, however, even below $1 \mathrm{~km}$ above the surface of the sea, wind blows strongly as friction is significantly smaller. Figure 5 shows the land and sea breezes caused by temperature differences in coastal areas.

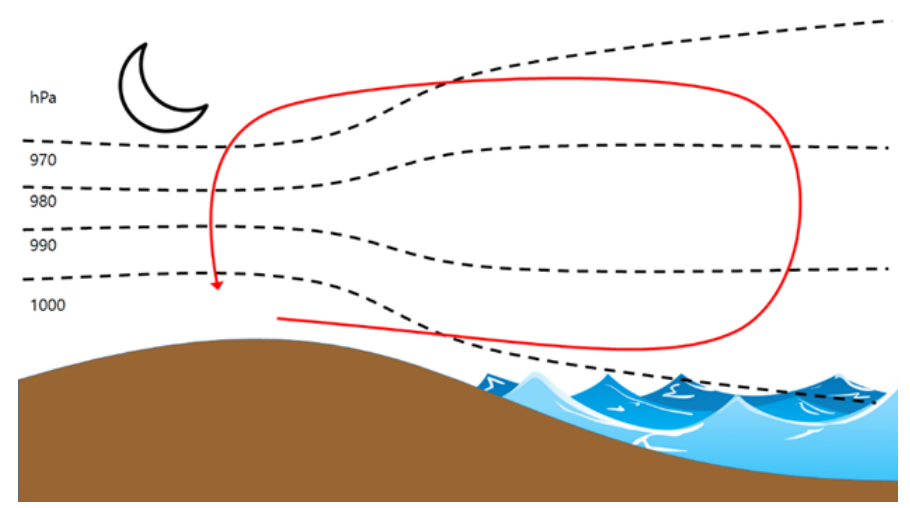

Fig 5. Sea breeze in coastal areas [14] 


\section{PREDICTION OF PROPAGATION PATH OF WIND TURBINE NOISE CONSIDERING TEMPERATURE AND GEOGRAPHICAL FEATURES}

\subsection{Propagation Path Prediction of Wind Turbine Noise in Mountainous Regions}

In Mountainous areas, wind turbines are commonly installed near the top of the mountain while residents reside in areas that are lower than the installation site. During the day, when the valley breeze blows from the valley to the top of the mountain, noise is refracted upwards due to the headwind of the noise propagation path. If the noise is propagated upwards, the amount of noise reaching the residents will be minuscule. At night, however, when the tailwind blows along the direction of the wind turbine noise, the noise is refracted and propagated to lower levels and can thus be transmitted easily to the residents. Figure 6 is an estimation of the propagation path of the wind turbine noise in mountainous areas.

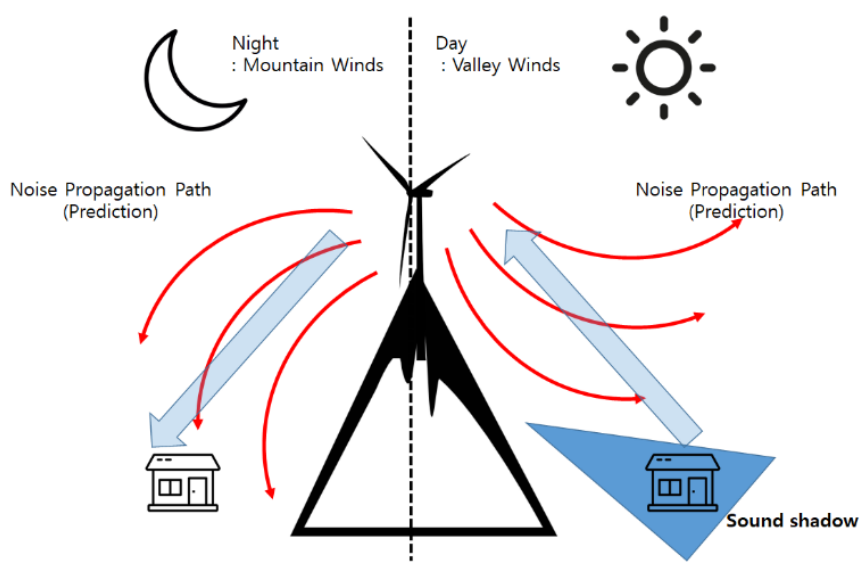

Fig 6. Propagation path prediction of wind turbine noise in mountainous areas

\subsection{Propagation Path Prediction of Wind Turbine Noise in Coastal Areas}

In coastal areas, wind turbines are installed offshore, and residents reside hundreds to thousands of meters away from wind turbines with the sea being between them. When the land breeze blows to the sea, the breeze blows as a headwind of the wind turbine noise, and the temperature near the sea surface is high and decreases in respect to height, thus refracting and propagating the noise as it passes the sea. As the noise is refracted higher, there is less noise reaching the residents residing near the coast.
During daytime when the sea breeze blows to the land, the propagation speed of the wind turbine noise is increased due to the tailwind. In the case of land, sound can be refracted to lower areas and spread farther due to the effects of a land breeze. However, unlike that of a land breeze, the friction of the sea surface during a sea breeze is very small compared to that of the ground surface, thus noise refraction to lower levels is decreased and does not propagate as far as that of land breeze.

As the sea breeze passes through the ocean and enters the land, the temperature near the surface of the land is hot and gets colder relative to height, hence sound is refracted and propagated upwards. Furthermore, winds are formed along the isotherm due to the density difference that occurs when the sea breeze enters the hot region to the cold region. The isotherm rises in the direction of the land when the sea breeze blows and generates wind, which in turn causes a difference in the propagation speed of noise thereby refracting the noise upwards [15].

Even if the sea breeze blows in the propagation path of the wind turbine noise, the coastal area has various geographical features to minimize noise damage by raising it upwards before reaching a residential area. Figure 7 estimates the propagation path of wind turbine noise in coastal areas.

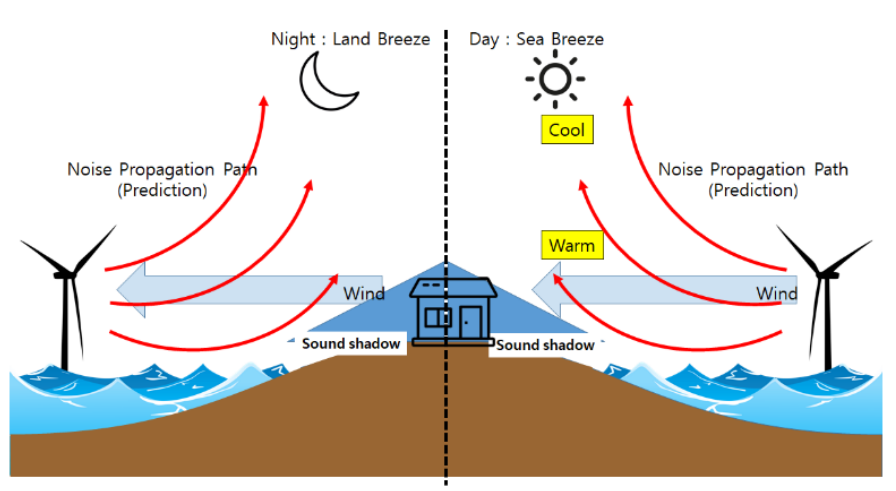

Fig 7. Propagation path prediction of wind turbine noise in coastal areas

\section{CONCLUSION}

New sources of energy are undoubtedly necessary in order to replace fossil fuels that have been depleted due to climate change caused by global warming. In that respect, wind power is a significantly appropriate novel renewable energy. However, low frequency noise of wind turbines causes environmental damage which is both physical and mental. Among others, one of the solutions to noise damage caused by wind turbine is offshore wind turbine. Offshore wind power 
uses geographical advantages of the sea to minimize noise damage.

In this study, the propagation path of wind turbine noise was predicted by geographical features of mountainous and coastal regions where wind turbines are installed. The effects of wind and noise propagation caused by geographical characteristics of mountainous and coastal regions were reflected to the propagation path of wind turbine noise to predict the influence of noise transmitted to the residents.

In mountainous areas, during the day, when there is a headwind in respect to the propagation path of the wind turbine noise, the noise is refracted upwards due to the effects of surface wind. During the night, when there is a tailwind, the noise is refracted downwards and propagates far due to the effects of the surface wind.

In coastal areas, when the land breeze blows at night, the temperature near the surface of the sea is high and becomes lower in respect to height, and the headwind against the wind turbine noise refracts the noise upwards as it propagates through the sea. During the day when sea breeze blows, the friction of the sea surface is low, propagating noise in all directions, and as the wind enters the land from the sea, the wind rises upward due to the thermal wind, causing the noise to refract upward. Additionally, noise that has reached the land is refracted upwards due to the temperature difference between the hot surface and cold upper level.

As a result of this prediction, wind turbines in mountainous areas mainly causes noise to spread far at night, causing significant damage, while wind turbines in coastal areas minimize noise by refracting it upwards during both day and night.

It is hoped that this study will help select the location of wind turbines to minimize noise damage to residents, and that it can be utilized as a technique for environmental analysis of noise damage prior to installing wind turbines.

\section{REFERENCE}

[1] Y. M. Park, K. K. Kang, K. M. Kim. Noise Environmental Impact Assessment and Management by Wind Power Plant(Wind Farm), Korea Environment Institue, Korea (2015).
[2] eo, K.-S., Bae, M.-J., "Suitability study of inter-floor noise measurement standards according to flooring materials", Information (Japan), Vol.18, No.4, 2015, pp. 1225-1229.

[3] Bong-Young Kim, Uk-Jin Song, Myung-Jin Bae, "A Study on Noise Components of Wind Power Plant Considering Sound Propagation Pathway", Convergence Research Letter of Multimedia Services Convergent with Art, Humanities, and Sociology, ISSN: 2384-0870, Vol.8, No.10, October (2018), pp.551-558.

[4] Bong-Young Kim and Myung-Jin Bae, "A Study on Sound Noise Control Method of Sound Fire Extinguisher with Wind", International Journal of Engineering Research and Technology, ISSN 0974-3154, Volume 12, Number 6 (2019), pp. 765-769.

[5] Doo-Heon Kyon, Myung-Jin Bae, "Analysis of Acoustic Psychology of City Traffic and Nature Sounds". The journal of the acoustical society of Korea, Vol.28, No.4, (2009), pp.356-362.

[6] The wind passed!, One and only earth (2016.11.04), EBS Korea.

[7] Bong-Young Kim, Myung-Jin Bae, "A Study on The Noise Masking of Wind Power Plant Noise by Wave Sound", Convergence Research Letter of Multimedia Services Convergent with Art, Humanities, and Sociology, ISSN: 2384-0870, Vol.6, No1, January (2018), pp.837-844.

[8] S. T. Lee. Principles and Application of Sound, Cheong Moon Gak, Korea (2004).

[9] Bong-Young Kim and Myung-Jin Bae, "A Study on the Effect of Wind Around on Sound Fire Extinguisher", International Journal of Engineering Research and Technology, ISSN 0974-3154, Vol.12, No.1, (2019), pp.97-101.

[10] Bong-Young Kim, Kwang-Bock You and Myung-Jin Bae, "A Study on Sound Energy Resonance Using the Special Acoustic Lens", International Journal of Engineering Research and Technology, ISSN 0974-3154, Vol.12, No.5, (2019), pp.642-646.

[11] Bong-Young Kim and Myung-Jin Bae, "A Study on Sound Beam Formation of Sound Fire Extinguisher", International Journal of Engineering Research and Technology, ISSN 0974-3154, Vol.12, No.7, (2019), pp.1014-1019.

[12] [https://www.scienceall.com/] Surface Wind.

[13] [https://www.scienceall.com/] Mountain and Valley Breeze.

[14] [Wikipedia.org] Sea and Land Breeze.

[15] [Wikipedia.org] Thermal Wind.

[16] Kim, M.-S., Bae, M.-J. "A study on a fire extinguisher with sound focus", Information (Japan), Vol.20, No.6, 2017, pp. 4055-4062. 